\title{
Ozone preconditioning and exposure to ketamine attenuates hepatic inflammation in septic rats
}

Wenchong Sun, Ling Pei

Department of Anesthesiology, First Affiliated Hospital of China Medical University, Shenyang, China

Submitted: 11 January 2011

Accepted: 16 August 2011

Arch Med Sci 2012; 8, 5: 918-923

DOI: 10.5114 /aoms.2012.29278

Copyright ( 2012 Termedia \& Banach

\section{Abstract}

Introduction: The objective of this study was to evaluate the interaction between ozone oxidative preconditioning and the anesthetic ketamine on cytoplasmic nuclear factor $\kappa \mathrm{B}(\mathrm{NF}-\kappa \mathrm{B})$ levels in a rat endotoxic shock model.

Material and methods: Forty Wistar rats were randomly divided into 5 groups: I - control group; II - rats intraperitoneally (i.p.) treated with LPS; III - rats treated with LPS and then treated with ketamine; IV - animals pre-treated with $\mathrm{O}_{3} / \mathrm{O}_{2}$ mixture for 5 days, then treated with LPS for $24 \mathrm{~h}$ followed by infusion with ketamine; $\mathrm{V}-\mathrm{O}_{3} / \mathrm{O}_{2}$ pre-treatment, as described above for IV, followed by LPS infusion, and then $0.9 \%$ saline. In addition to histological examination of the liver, the levels of NF- $\kappa B$ were determined by SABC immunohistochemistry in each group.

Results: Histological damage was observed in the lipopolysaccharide (LPS) group. It was characterized by hepatic disarray, hepatic lobule distortion, congestion of liver sinusoids, hepatocyte swelling and necrosis, and granulocyte infiltration. These changes were not obvious in the $\mathrm{O}_{3} / \mathrm{O}_{2}+\mathrm{LPS}+$ ketamine group. The normal control group had low activity of NF-kB, but that activity was markedly increased in the LPS group $(p<0.05)$. The NF- $\kappa B$ level was significantly decreased in the $\mathrm{O}_{3} / \mathrm{O}_{2}+\mathrm{LPS}+$ ketamine group $(p<0.05)$ when compared with the ketaminetreated group, and was almost equal to the control group.

Conclusions: We confirmed that the preconditioning effect of ozone enhances the biological effectiveness of ketamine by altering NF-kB activity, which may play an important role in sepsis-induced liver injury in rats.

Key words: ketamine, ozone, liver injury, nuclear factor $\kappa B$, rat, sepsis.

\section{Introduction}

Sepsis is a complication related to extensive trauma, shock, and major surgery, often leading to multiple organ failure and death. It can be activated by infection with Gram-negative bacteria, and it frequently activates a series of signal-transduction pathways, which lead to an excessive inflammatory reaction [1]. It is well known that numerous cytokines are induced by inflammation, and the network (or cascade) triggered is rather complex.

Nuclear factor $\kappa \mathrm{B}(\mathrm{NF}-\kappa \mathrm{B})$ represents an important group of regulators in a broad range of genes involved in cellular responses to inflammatory signals [2]. As a pro-inflammatory transcription factor, it can bind to specific sequences in the promoter regions of many pro-inflammatory genes (such as TNF- $\alpha$ and IL-6) which are important in inducing the acute inflamma-
Corresponding author:

Pei Ling

Department of Anesthesiology First Affiliated Hospital of China Medical University 155 North Nanjing Street Shenyang 110001 PR China

E-mail: lingpei49@vip.sina.com 
tory response associated with critical illnesses [3]. Consequently, NF- $\kappa \mathrm{B}$ occupies a central role in modulating immuno-regulatory responses, in both animal models and clinical practice. The NF-kB was an important factor in the development of liver diseases. In the development of hepatic inflammation, activation of Kupffer cells contributes to the release of a large quantity of reactive oxygen species (ROS) which stimulates NF-кB [4]. The increased activation of NF- $\kappa B$ results in enhanced transcription of pro-inflammatory genes, which amplifies the signals, accelerating a chemical cascade of reactions [4]. Therefore, it has been suggested that NF-кB plays an essential role during the acute phase of liver injury [5]. Paterson et al. [6] showed that there was a definite relationship between the activity of NF- $\kappa \mathrm{B}$ in granulocytes and neutrophils, and the mortality of patients suffering from systemic inflammatory response syndrome (SIRS). This indicates that NF- $\kappa B$ activity increases enormously in the early phase before the clinical diagnostic criteria of SIRS have been met. Therefore, further understanding of NF- $\mathrm{KB}$ regulation will be important in preventing or minimizing acute inflammatory injury, and in finding an effective means to protect the liver.

Ketamine is a unique agent which possesses anesthetic, sedative, and analgesic properties in addition to its potent ability to suppress pro-inflammatory gene expression. Several investigators have determined that ketamine possesses anti-inflammatory activity [7-12]. Takenaka et al. [7] have shown that ketamine diminished liver injury caused by lipopolysaccharide (LPS), and that this effect was accompanied by inhibition of NF- $\mathrm{KB}$ activation. Sun et al. [8] have demonstrated that ketamine has a suppressive effect on NF- $\kappa \mathrm{B}$ activation after endotoxin exposure in vitro and in vivo.

Although ozone is one of the most potent of all disinfectants, it often cannot inactivate pathogens in vivo because pathogens can be well protected by a powerful antioxidant system [13]. Ozone acts as a mild enhancer of the immune system by stimulating the synthesis of some cytokines [14]. Ozone reacts as soon as it is dissolved in plasma, and forms reactive oxygen species (ROS) and lipid oxidation products (LOPS) [15]. The crucial messenger ROS molecule is hydrogen peroxide $\left(\mathrm{H}_{2} \mathrm{O}_{2}\right)$, which diffuses easily into the cytoplasm of mononuclear cells. Its sudden appearance in the cytoplasm acts as a shortacting ozone messenger responsible for activating tyrosine kinase which phosphorylates NF- $\kappa \mathrm{B}$, allowing the release of a heterodimer $(p 50+p 65)$, and eventually causing the synthesis of several proteins, among which are the acute-phase reactants and numerous interleukins [16]. Sen and Baltimore [17] first demonstrated that a sudden surge of intracytoplasmic $\mathrm{H}_{2} \mathrm{O}_{2}$ was responsible for the activation of NF- $\kappa$ B. By acting as long-distance messengers,
LOPs can transmit the signal of an acute oxidative stress to all organs. Pawel [18] proposed that an ozone/oxygen mixture injected i.p. can restrict the development of septic shock by inhibiting NF-KB activation. The protective effects of ozone pre-conditioning are anti-inflammation, anti-oxidation, inhibition of cell apoptosis, and restriction of excessive oxidative stress caused by sepsis resulting in physiological intracellular balance between reduction and oxidation (redox) [19].

Ozone has been widely used in clinical therapy (especially in acute and chronic infectious diseases $[20,21])$. However, to our knowledge, there is little information available in the literature about its interaction with other anti-inflammatory drugs. We therefore hypothesized that the efficacy of ketamine could be influenced by ozone pre-conditioning through attenuation of NF- $\kappa B$ activity. To test this hypothesis, we measured NF- $\kappa B$ levels and examined the histology of the liver in endotoxin-exposed rats.

\section{Material and methods}

Adult male Wistar rats $(n=40)$, weighing 230-250 g, used in this experiment were purchased from China Medical University, Shenyang, China. All animals were housed at room temperature, in iron cages, one group per cage, under $12 \mathrm{~h}$ artificial light/dark cycles [22]. Animals had free access to the standard laboratory chow and water. The study was approved by the Medicine Animal Studies Committee of China Medical University and was conducted according to China Medical University policy on animal experimentation.

\section{Experimental protocols}

All animals were allocated randomly to one of five groups (eight per group):

I. A normal saline (NS) control group in which animals received $0.2 \mathrm{ml}$ of $0.9 \% \mathrm{NS}(1 \mathrm{ml} / \mathrm{kg}$ body weight, i.p.).

II. A lipopolysaccharide (LPS) group in which rats were treated with an intraperitoneal (i.p.) injection of LPS from Escherichia coli 055:B5 at a dose of $20 \mathrm{mg} / \mathrm{kg}$ body weight (LPS in $2.5 \mathrm{ml} \mathrm{NS}$ ), and then injected with $0.2 \mathrm{ml} \mathrm{NS}$.

III. A ketamine-treated group injected i.p. with LPS $20 \mathrm{mg} / \mathrm{kg}(2.5 \mathrm{ml})$ followed immediately by ketamine $5 \mathrm{mg} / \mathrm{kg}$, i.p. $(0.2 \mathrm{ml})$.

IV. An $\mathrm{O}_{3} / \mathrm{O}_{2}+\mathrm{LPS}+$ ketamine group treated with $2 \% \mathrm{O}_{3} / 98 \% \mathrm{O}_{2}$ produced by an Ozone Generator (Humazon, Germany) at a concentration of $2 \%$ (vol) $(0.5 \mathrm{mg} / \mathrm{kg}$, i.p.) $(1 \mathrm{ml})$ from gaseous medical oxygen injected for 5 days followed by an infusion of LPS (20 mg/kg) $(2.5 \mathrm{ml}) 24 \mathrm{~h}$ after the last infusion. This was followed by an injection of ketamine $(5 \mathrm{mg} / \mathrm{kg}$, i.p. $)(0.2 \mathrm{ml})$.

V. An $\mathrm{O}_{3} / \mathrm{O}_{2}+\mathrm{LPS}+\mathrm{NS}$ group treated with $\mathrm{O}_{3} / \mathrm{O}_{2}$ gas mixture $(1 \mathrm{ml})$, and injected with LPS $(2.5 \mathrm{ml})$ as described above followed by $0.2 \mathrm{ml}$, NS injected i.p. 
Table I. Quantitation of NF-кB in sepsis-induced liver injury in rats $(x \pm s, n=8)$

\begin{tabular}{|lcc|}
\hline Treatment & Number & NF-кB \\
\hline Normal saline group & 8 & $7.467 \pm 6.073$ \\
\hline LPS group & 8 & $37.139 \pm 19.294 \&$ \\
\hline Ketamine-treated group & 8 & $12.500 \pm 4.685^{*}$ \\
\hline $\mathrm{O}_{3} / \mathrm{O}_{2}+\mathrm{LPS}+$ ketamine group & 8 & $8.213 \pm 3.438^{* \#}$ \\
\hline $\mathrm{O}_{3} / \mathrm{O}_{2}+\mathrm{LPS}+$ NS group & 8 & $8.889 \pm 2.716^{* \#}$ \\
\hline
\end{tabular}

${ }^{\star} p<0.05$ vs. group I, ${ }^{*} p<0.01$ vs. group II, ${ }^{*} p<0.05$ vs. group III by Dunnett $t$-test. The blood samples were taken to measure NF- $\kappa B$ levels in serum $2 \mathrm{~h}$ after the last treatment

All rats were killed $2 \mathrm{~h}$ later by injection i.p. of $100 \mathrm{mg}$ pentobarbital sodium. Liver fragments were harvested during autopsy, and immediately fixed in buffered formalin ( $\mathrm{pH}$ 7.2) for paraffin embedding and hematoxylin-eosin staining [23]. Hepatic histology was evaluated under a BX-51 optical microscope (Olympus, Japan) by three independent experienced histologists who were blinded to the experimental groups. Sections $(5-6 \mu \mathrm{m})$ for immunohistochemistry [24] were mounted on slides and incubated at $60^{\circ} \mathrm{C}$ for $30 \mathrm{~min}$. The specimens were deparaffinized with xylene, rehydrated, rinsed, and washed in PBS ( $\mathrm{pH} 7.4)$ for
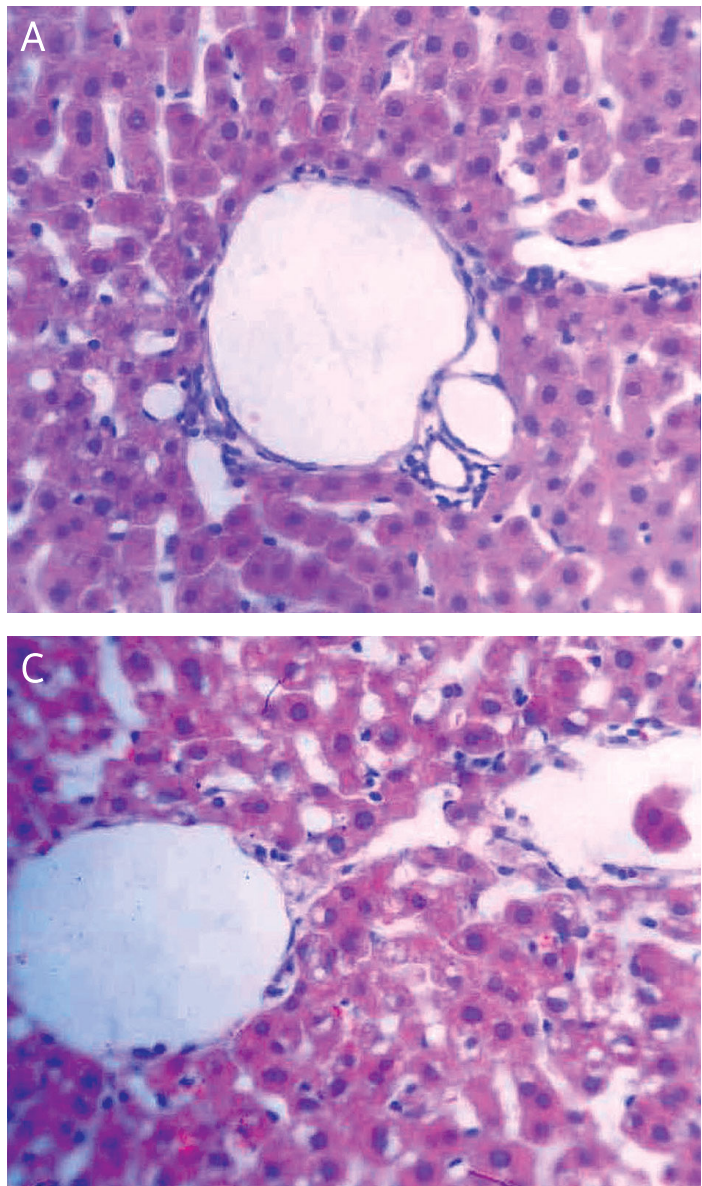

$30 \mathrm{~min}$. The tissue samples were incubated for $20 \mathrm{~min}$ with monoclonal antibody against rat NF-кB p65 (1: 250) (Boster Biotechnology, China). The expected molecular weight of rat NF- $\kappa \mathrm{B}$ p65 is $70 \mathrm{kDa}$. All the antibodies were pre-diluted in Dako diluent with background-reducing solution before incubation. The immunohistochemical reaction was carried out according to the manufacturer's instructions.

\section{Statistical analysis}

Data were expressed as mean \pm SEM (eight per group). Statistical significance was determined by one-way analysis of variance (ANOVA) using SPSS 11.5. Differences between groups at baseline were analyzed by a Dunnett $t$-test. Value of $p<0.05$ was considered statistically significant.

\section{Results}

In all experiments, no causes of mortality were observed other than repeated infusion of the ozone/ oxygen mixture or solution.

1) Under the microscope, the presence of NF- $\kappa B$ was visualized as buffy granules in the cytoplasm
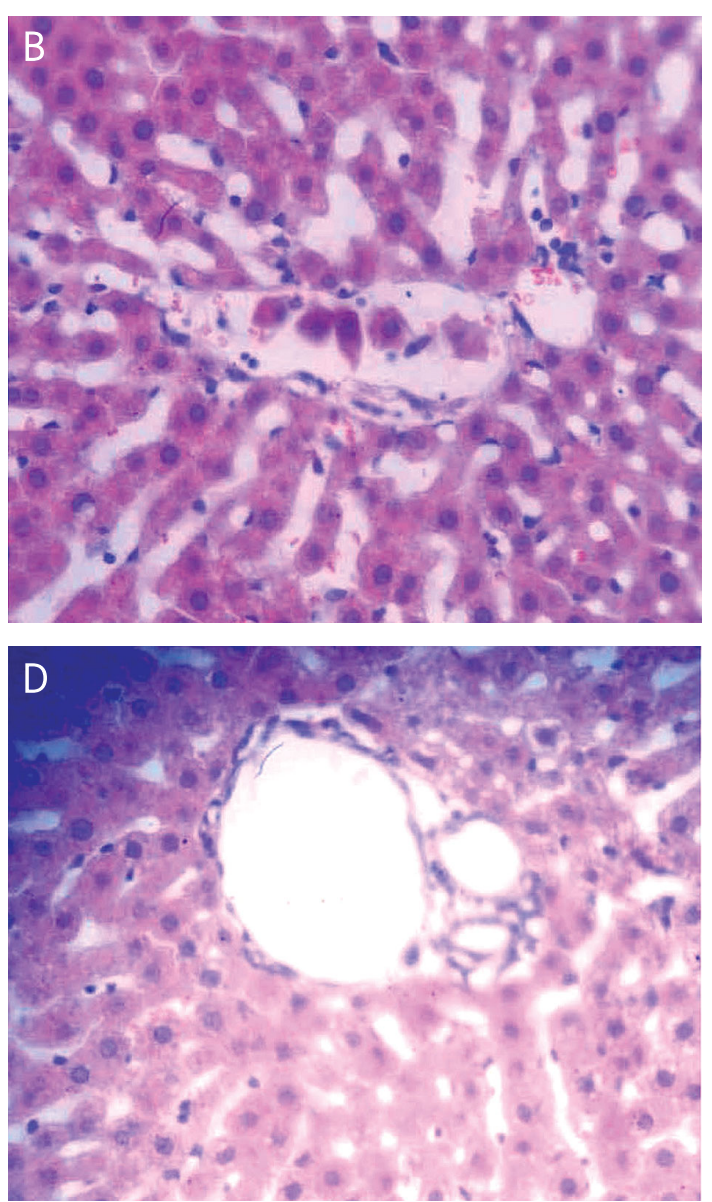

Figure 1. Histological damage in the sepsis model. A - Normal saline group; treated with an i.p. injection of LPS in 2.5 $\mathrm{ml} \mathrm{NS}$. B - LPS group; treated with LPS $(2.5 \mathrm{ml})$ and then treated with ketamine $(0.2 \mathrm{ml})$. C - Ketamine group; treated with $\mathrm{O}_{3} / \mathrm{O}_{2}$ gas mixture $(1 \mathrm{ml})$ for 5 days followed by an infusion of LPS $(2.5 \mathrm{ml}) 24 \mathrm{~h}$ after the last infusion, and then an injection of ketamine $(0.2 \mathrm{ml})$. D $-\mathrm{O}_{3} / \mathrm{O}_{2}+\mathrm{LPS}+$ ketamine group $(\mathrm{H}+\mathrm{E} 400 \times)$ 

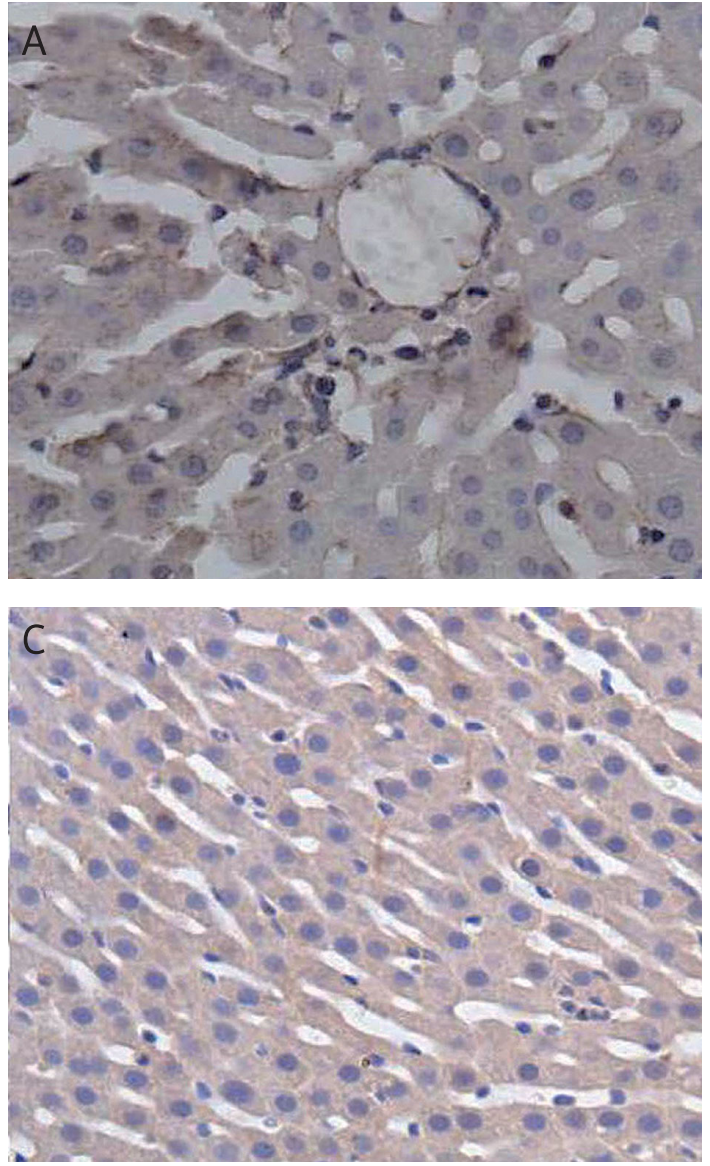

or the nucleus of hepatocytes. The optical density value and locations are shown in Table I. Group I had quite low NF-אB staining, but this was markedly increased after LPS injection in group II $(p<0.05)$. The NF- $\kappa B$ levels in groups III, IV, and $\checkmark$ were significantly decreased compared with group II $(p<0.01)$. The NF- $\mathrm{BB}$ levels were significantly decreased in group IV $(p<0.05)$ compared with group III, and almost equal to group I, but this difference was not statistically significant $(p>0.05)$.

2) In group II, under the light microscope, histological damage was observed which was characterized by disturbance of hepatic architecture, hepatic lobule distortion, congestion in liver sinusoids, hepatocyte swelling and necrosis, karyorrhexis and karyolysis, granulocyte infiltration, and accumulation (Figure 1 B). In group I, the morphology of hepatic lobules and hepatocytes was completely normal, without neutrophilic granulocyte infiltration (Figure 1 A). In group IV, the hepatocytes were slightly swollen and distended. The liver sinusoids were mildly expanded, but hepatic architecture was intact, with normal liver cell membrane integrity, and little inflammatory cell infiltration (Figure 1 D). Groups III and V displayed intact liver architecture, but hepatocytes were swollen and distended, with hydropic degenera-

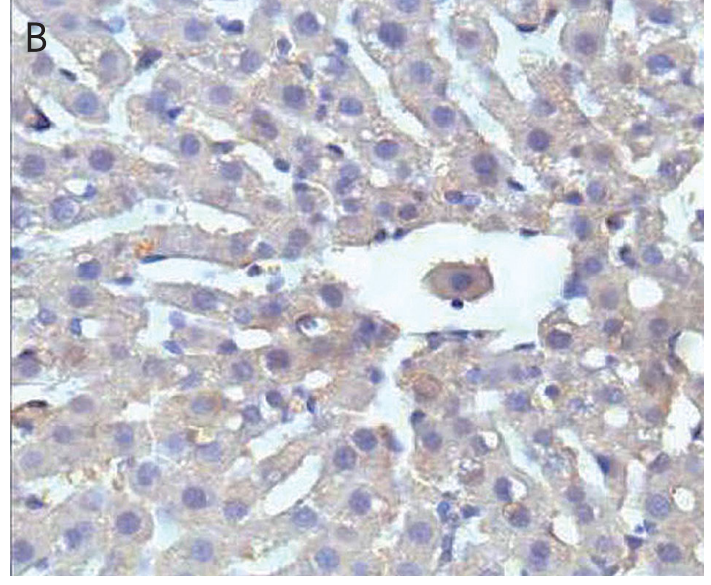

Figure 2. Immunohistochemical staining in the sepsis model. Liver tissue samples for immunohistochemistry were incubated to determine the levels of NF- $\mathrm{KB}$ after i.p. injection of LPS. A - LPS group; treated with LPS $(2.5 \mathrm{ml})$ and then treated with ketamine $(0.2 \mathrm{ml})$. B - Ketamine group; treated with $1 \mathrm{ml} \mathrm{O}_{3} / \mathrm{O}_{2}$ gas mixture for five days followed by LPS $(2.5 \mathrm{ml})$ $24 \mathrm{~h}$ after the last infusion, and then an injection of ketamine $(0.2 \mathrm{ml}) . \mathrm{C}-\mathrm{O}_{3} / \mathrm{O}_{2}+\mathrm{LPS}+$ ketamine (DAB staining, 400x)

tion of some liver cells, compressed sinusoids, and a great quantity of inflammatory cells distributed in hepatic tissue (Figure $1 \mathrm{C}$ ).

3) Immunohistochemical staining showed that in group II, there was NF-кB-positive staining in the cytoplasm and nuclei of hepatocytes, which showed buffy granulation (Figure $2 \mathrm{E}$ ). In group III, the staining of NF- $\kappa B$ was less than in group II (Figure 2 F). Furthermore, the levels were significantly decreased in group IV compared with groups II and III (Figure $2 \mathrm{G}$ ).

\section{Discussion}

In the current study, we focused on the local expression of the transcription factor NF- $\kappa B$ in the livers of rats in the setting of sepsis. The study de-

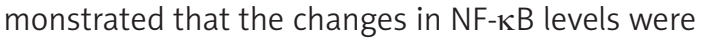
consistent with the histological changes in liver tissues. This suggests that NF- $\mathrm{B}$ B plays a pivotal role in the liver injury that occurs in septic rats. We assessed NF- $\kappa B$ because that transcription factor may be a marker of inflammatory response, immune reaction, and cell apoptosis [25]. It has been shown that inhibitors of NF-KB possess therapeutic potential in individuals with inflammation or tumor development [26]. A better understanding of the role of NF- $\kappa B$ is important in designing future therapies to 
prevent or minimize acute inflammatory injury associated with critical illness.

The current experiments also showed that ketamine independently suppresses NF- $\mathrm{\kappa B}$ activation in the liver after endotoxin stimulation, which is consistent with a previous report by Taniguchi et al. [27]. With regard to the dose selection, $5 \mathrm{mg} / \mathrm{kg}$ ketamine is within the clinically effective range [28]. There is evidence that high doses of ketamine are toxic [29], and a dose of $10 \mathrm{mg} / \mathrm{kg}$ can cause reversible damage to the liver and kidneys in cats and dogs [30]. Because we wanted to focus mainly on the therapeutic effect, we selected $5 \mathrm{mg} / \mathrm{kg}$.

Intraperitoneal injection of an $\mathrm{O}_{3} / \mathrm{O}_{2}$ mixture might produce a direct effect on peritoneal macrophages which generates the first line of defense against bacteria and/or its toxins. This in turn can cause the release of a variety of cytokines such as tumour necrosis factor $\alpha$ (TNF- $\alpha)$, interleukin $\alpha$ (IL- $\alpha)$, and interferon $\alpha$ (IFN- $\alpha$ ), influencing the outcome of severe infections [31]. Although it acts as an oxidant, ozone also enhances the anti-oxidant capacity for overcoming critical inflammatory infections. Therefore, ozone concentrations can be beneficial or toxic [13]. The usual total dose of ozone in rats ranges from 0.5 to $1 \mathrm{mg} / \mathrm{kg}$ (i.e., 500 to $1000 \mu \mathrm{g} / \mathrm{kg}$ ). To avoid toxicity, we choose the lower threshold of $500 \mu \mathrm{g} / \mathrm{kg} \mathrm{O}_{3} / \mathrm{O}_{2}$, which when administered intraperitoneally can inhibit the progress of sepsis. Furthermore, the applied dose of the gas mixture in our experiments was sufficiently high to permit detection of the therapeutic anti-inflammatory effects on the liver. A previous article [32] reported an inverse relationship between the dose of ozonized oxygen and the survival rate, with the lowest dose of ozone exhibiting the greatest effect on survival.

In conclusion, the data indicate that decreases in NF- $\kappa \mathrm{B}$ levels are associated with ketamine-mediated amelioration of liver histological damage during sepsis. Administration of an $\mathrm{O}_{3} / \mathrm{O}_{2}$ mixture in septic rats may play an important role in minimizing liver injury. This amelioration of damage may be due to the regulation of cellular redox balance or a reduction in the incidence of sepsis. Based on these and other animal experiments on ozone [33], we speculate that pre-conditioning of patients by intraperitoneal injection of an $\mathrm{O}_{3} / \mathrm{O}_{2}$ gas mixture, especially when combined with ketamine, can improve the prognosis in sepsis.

\section{Acknowledgments}

This project was supported by the Specialized Research Fund for the Doctoral Program of Higher Education of China in 2007 (Grant No. 20070159020) and the NSFC (Natural Science Foundation of China) (Grant No. s30471666). Also, we thank Medjaden Bioscience Limited for assisting in the preparation of this manuscript.

\section{References}

1. Lamontagne F, Briel M, Duffett M, et al. Systematic review of reviews including animal studies addressing therapeutic interventions for sepsis. Crit Care Med 2010; 38: 2401-8.

2. Abraham E. NF-kappaB activation. Crit Care Med 2000; 28 (4 suppl.): n100-4.

3. Cavaillon JM, Adib-Conquy M, Fitting C, Adrie C, Payen D. Cytokine cascade in sepsis. Scand I Infect Dis 2003; 35: 535-44.

4. Mercurio F, Manning AM. Multiple signals converging on NF-kappaB. Curr Opin Cell Biol 1999; 11: 226-32.

5. Czaja MJ. Cell signaling in oxidative stress-induced liver injury. Semin Liver Dis 2007; 27: 378-89.

6. Paterson RL, Galley HF, Dhillon JK, Webster NR. Increased nuclear factor kappa B activation in critically ill patients who die. Crit Care Med 2000; 28: 1047-51.

7. Takenaka I, Ogata M, Koga K, Matsumoto T, Shigematsu A. Ketamine suppresses endotoxin-induced tumor necrosis factor alpha production in mice. Anesthesiology 1994; 80: 402-8.

8. Sun J, Wang XD, Liu H, Xu JG. Ketamine suppresses intestinal NF-kappa B activation and proinflammatory cytokine in endotoxic rats. World J Gastroenterol 2004; 10: 1028-31.

9. Kawasaki T, Ogata M, Kawasaki C, Ogata J, Inoue Y, Shigematsu A. Ketamine suppresses proinflammatory cytokine production in human whole blood in vitro. Anesth Analg 1999; 89: 665-9.

10. Roytblat L, Talmor D, Rachinsky M, et al. Ketamine attenuates the interleukin- 6 response after cardiopulmonary bypass. Anesth Analg 1998; 87: 266-71.

11. Li CY, Chou TC, Wong CS, et al. Ketamine inhibits nitric oxide synthase in lipopolysaccharide-treated rat alveolar macrophages. Can J Anaesth 1997; 44: 989-95.

12. Domino EF, Zsigmond EK, Domino LE, Domino KE, Kothary SP, Domino SE. Plasma levels of ketamine and two of its metabolites in surgical patients using a gas chromatographic mass fragmentographic assay. Can Anesth Analg 1982; 61: 87-92.

13. Bocci V. The case for oxygen-ozonetherapy. Br J Biomed Sci 2007; 64: 44-9.

14. Bocci V, Valacchi G, Corradeschi F, Fanetti G. Studies on the biological effects of ozone: 8 . Effects on the total antioxidant status and on interleukin- 8 production. Mediators Inflamm 1998; 7: 313-7.

15. Bocci V, Luzzi E, Corradeschi F, Paulesu L, Di Stefano A. Studies on the biological effects of ozone: 3. An attempt to define conditions for optimal induction of cytokines. Lymphokine Cytokine Res 1993; 12: 121-6.

16. Bocci V, Di Paolo N. Oxygen-ozone therapy in medicine: an update. Blood Purif 2009; 28: 373-6.

17. Sen R, Baltimore D. Multiple nuclear factors interact with the immunoglobulin enhancer sequences. Cell 1986; 46: 705-16.

18. Madej P, Plewka A, Madej JA, et al. Ozonotherapy in an induced septic shock. I. Effect of ozonotherapy on rat organs in evaluation of free radical reactions and selected enzymatic systems. Inflammation 2007; 30: 52-8.

19. Verrazzo G, Coppola L, Luongo C, et al. Hyperbaric oxygen, oxygen-ozone therapy, and rheologic parameters of blood in patients with peripheral occlusive arterial disease. Undersea Hyperb Med 1995; 22: 17-22.

20. Bocci VA. Scientific and medical aspects of ozone therapy. State of the art. Arch Med Res 2006; 37: 425-35.

21. Bocci V. Biological and clinical effects of ozone. Has ozone therapy a future in medicine? Br J Biomed Sci 1999; 56: 70-9.

22. Suzuki H, Hasegawa Y, Chen W, Kanamaru K, Zhang JH. Recombinant osteopontin in cerebral vasospasm after subarachnoid hemorrhage. Ann Neurol 2010; 68: 650-60. 
23. Glover LE, Newton K, Krishnan G, et al. Dysferlin overexpression in skeletal muscle produces a progressive myopathy. Ann Neurol 2010; 67: 384-93.

24. Cibelli M, Fidalgo AR, Terrando N, et al. Role of interleukin-1beta in postoperative cognitive dysfunction. Ann Neurol 2010; 68: 360-8.

25. Chabot-Fletcher M. A role for transcription factor NF-kappa B in inflammation. Inflamm Res 1997; 46: 1-2.

26. Sun Z, Andersson R. NF-kappaB activation and inhibition: a review. Shock 2002; 18: 99-106.

27. Taniguchi T, Takemoto Y, Kanakura H, Kidani Y, Yamamoto K The dose-related effects of ketamine on mortality and cytokine responses to endotoxin-induced shock in rats. Anesth Analg 2003; 97: 1769-72.

28. Song XM, Li JG, Wang YL, et al. Effects of ketamine on proinflammatory cytokines and nuclear factor kappaB in polymicrobial sepsis rats. World J Gastroenterol 2006; 12 : 7350-4.

29. Sun J, Li F, Chen J, Xu J. Effect of ketamine on NF-kappa B activity and TNF-alpha production in endotoxin-treated rats. Ann Clin Lab Sci 2004; 34: 181-6.

30. Madej JA, Stańczyk JF. Effect of ketamine anaesthesia on enzyme activity in organs of dogs and cats. Anaesth Resusc Intensive Ther 1975; 3: 297-303.

31. Canning BJ, Hmieleski RR, Spannhake EW, Jakab GJ. Ozone reduces murine alveolar and peritoneal macrophage phagocytosis: the role of prostanoids. Am J Physiol 1991; 261: L277-282.

32. Jimba M, Skornik WA, Killingsworth CR, Long NC, Brain JD, Shore SA. Role of C fibers in physiological responses to ozone in rats. J Appl Physiol 1995; 78: 1757-63.

33. Schulz S, Rodriguez ZZ, Mutters R, Menendez S, Bette M. Repetitive pneumoperitoneum with ozonized oxygen as a preventive in lethal polymicrobial sepsis in rats. Eur Surg Res 2003; 35: 26-34. 